\title{
Towards Imposing Load Shedding Hierarchies based on Tokenised Self Assessed Licenses
}

\author{
Almero de Villiers \\ School of Electrical and Electronic Engineering \\ University College Dublin \\ Dublin, Ireland \\ almero.devilliers@ucdconnect.ie
}

\author{
Paul Cuffe \\ School of Electrical and Electronic Engineering \\ University College Dublin \\ Dublin, Ireland \\ paul.cuffe@ucd.ie
}

\begin{abstract}
This piece serves as an exploratory study into the combination of blockchain-aware smart meters and radical economic paradigms. Load shedding is examined through this novel lens. Load shedding is an established means of preventing system collapse under emergency conditions. An auctioned load shedding hierarchy method is proposed whereby participating parties bid on tokens (SALtoks) guaranteeing access to supply during load shedding. This method is based on the recently developed Self Assessed Licenses Sold via Auction paradigm developed. Under this paradigm, SALtoks are subject to taxes based on valuations, while also being subject to continuous auction. A case study is performed on a hypothetical island power system. Higher ranking SALtoks are held by larger consumers. The method is found to mitigate economic impacts by allowing industry to maintain supply during load shedding. Smaller consumers, while subject to more frequent interruptions, gain the public benefit of increased income from taxation.
\end{abstract}

Keywords-load shedding, blockchain, smart contracts, tokenised energy

\section{INTRODUCTION}

Since the early days of electricity, power grids have been vulnerable to complete collapse when emergency situations occur. In the case where demand sharply exceeds capacity, likely due to failure of generation or transmission lines, load shedding is a proven short-term demand-response solution, with literature on the subject stretching back to the 1950s [1]. The term refers to the act of intentionally removing part of the total load so as to match generation with demand. This is done to limit the chance of system-wide failure and voltage collapse or frequency diminution [2].

In regions with long-term mismatch between demand and supply, such as some developing nations, regular load shedding (or rolling blackouts) become more commonplace. However, even in more stable power systems, emergency load shedding is an always-present threat. Load shedding has been shown to have dire economic impacts [3]. The process usually occurs in the form of equally distributed rolling blackouts, although it has been argued that low-income neighbourhoods are more

This publication has been funded by the Sustainable Energy Authority of Ireland under the SEAI Research, Development \& Demonstration Funding Programme 2018, grant number 18/RDD/373. Interests disclosure: the authors hold cryptographic assets. likely to be disconnected first [4]. A novel blockchain-based mechanism may be able to mitigate the economic impacts of load shedding, while also providing benefits to smaller underprivileged consumers in the form of increased public funding.

1) Under-Voltage and Under-Frequency Load Shedding: Load shedding can be implemented based on drastic drop in either grid voltage or frequency. Under-Voltage Load Shedding is the method of decreasing load based on the occurrence of sustained drops below grid voltage [5]. This serves to minimise potential damage to infrastructure [6]. Similarly, Under-Frequency Load Shedding refers to schemes based on sudden drops in grid frequency as a sign of excessive load [7]. Both schemes operate by observing a lower threshold.

2) Existing Load-Shedding Hierarchies: Some existing systems will shed load based on the location of branches that are drawing excessive capacity [1]. Automatic relays that disconnect when an under-frequency case have been present in power systems for decades [8]. Some arrangements have gone a step further and suggested partially shedding non-essential consumer loads [9]. Parsetijo et al. develop a scheme whereby shedding is concentrated locally to generation loss, with nearby substations being removed [10]. On a secondary level, they propose local load shedding at substations that have potential fast frequency decline rates as well as a corresponding large effect on reducing voltage [10].

Briefly, Moors et al. determine the most effective order of purely under-voltage load shedding by constructing a two dimensional load space. By calculating the Euclidean distance, the effectiveness of shedding each bus is determined [11]. In the 2008 paper, Nikoladis et al. construct a method of load shedding by examining the various sensitivities of power system nodes. These sensitivities consist of voltage with respect to load parameters, as well as loadability margins [7]. When an emergency occurs, nodes are shed in order of least to most sensitive until the necessary demand reduction is met.

3) Radical Market Arrangements for Load Shedding: An ethical and effective load shedding scheme may be realised by incorporating ideas and concepts from the field of radical marketplace design. Based on the property taxation scheme developed by Sun Yat-sen [12], Arnold Harberger proposes a self-assessment based model. Property owners are free to 
choose the listed value of their land, but are taxed proportionally on this appraisal [13]. Owners are compelled to sell to any party that exceeds their self-valuation. This method serves as a potential solution to monopoly on land, but also increases government revenue, theoretically resulting in an increase in social good.

Harberger's taxation method was further refined in [14], forming the basis of their Common Ownership Self-assessed Tax (COST) mechanism. Property remains self-assessed and is continually up for auction to any party that outbids the standing self-appraisal. This aims to ensure that property is always in the hands of those who most value it most highly, along with the additional above-mentioned advantages [15]. This new tax would serve to replace other taxes on capital, such as capital gains or corporation tax [15]. Furthermore, income taxes could be largely reduced, along with public debt. These steps may lead to a dramatic increase in social dividend and public infrastructure funding [15].

This piece will examine the use of a SALSA (Self Assessed Licenses Sold via Auction)-based hierarchy implemented via blockchain-enabled smart meters. The SALSA paradigm is as an evolution of the COST method developed in [14]. This is proposed as a way of allocating public licenses, subject to the same self-evaluation as in COST, with emphasis on the continual period auctions. As with land ownership in the COST method above, SALSA ensures that the sole license owner best values their ownership. The method has been put forward as a more ethical model of allotment in cases such as public facility use, natural resources [15], [16] and electromagnetic spectrum auction [17]. Although there are a number of potential radical markets mechanisms that may be explored, this piece will examine the interaction of cyber-physical systems with smart contract ecosystems. SALSA could provide a means of load shedding in an effective and ethical way, while allowing consumers who act as economic drivers to maintain their supply. This may mitigate some negative economic impacts.

This piece serves as an exploratory study linking two radical paradigms. The first of these paradigms is the concept of blockchain-aware smart meters that can observe and act on the state of a smart contract as well as physical grid conditions (such as voltage and frequency). This smart contract facilitates the holding and movement of tokenised guarantees of electricity service, responding appropriately to the canonical blockchain record. Tokenised energy trade has been the topic of previous studies [18], [19], but this piece interprets the concept in a novel way. The second radical paradigm that is examined is that of a progressive and disruptive economic mechanism, in the form of SALSA. This dictates the transfer and instantaneous state of token ownership. Smart contractbased economic instruments have been examined in previous studies [20], [21], but, again, this piece takes a novel approach.

4) Rate of Change of Frequency: The Rate Of Change Of Frequency $(R O C O F)$ of a system is a measure of how the system reacts to changes in demand and supply. The ROCOF is dependent on the inertia of system. This value is derived from the moment of inertia of rotating machines, while also considering the rated frequency and power imbalance. ROCOF

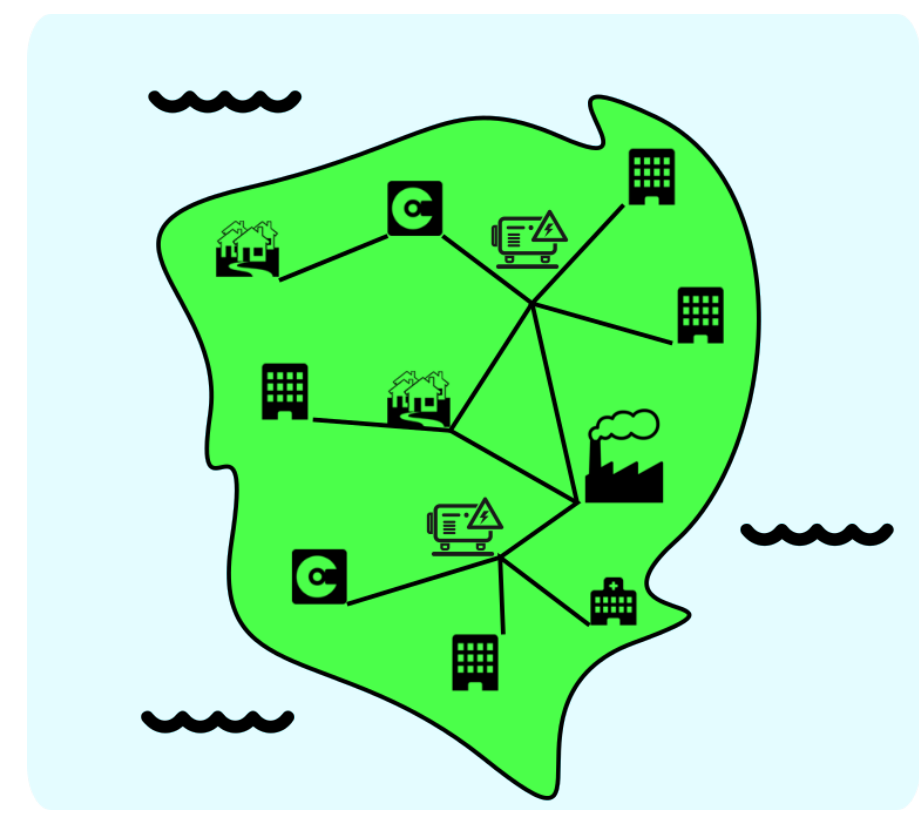

Fig. 1. Notional island power system used as case study

is calculated as in Equation 1 [22].

$$
\frac{d f}{d t}=-\Delta P \frac{f_{n}}{2 H S}
$$

where:

- $f_{n}$ is the rated system frequency,

- $H$ is total system inertia,

- $\quad S$ is rated system power and

- $-\Delta P$ is the power imbalance after the disturbance.

\section{Methodology}

This piece proposes SALSA as a basis for establishing a smart load shedding hierarchy. Inspired by electromagnetic spectrum allocation as in [17], parties can compete for SALSAtokens representing access to electricity within different levels of load shedding. These SALtoks serve as a a guarantee of supply within a certain frequency range, based on under-frequency load shedding. SALtoks can be viewed as a form of tokenised energy, that can be traded, stored and transferred via an established public smart contract with means of communicating with smart metering systems. When a SALtok is assigned to a user on this public smart contract, their order in the hierarchy of load shedding is changed. Otherwise, when the smart meter senses specific under-frequency conditions, a breaker is opened and the user is removed from supply. The ranked SALtoks thus represent a "queue", with higher valued SALtoks being the last to be removed from supply. All participants are free to bid on existing SALtoks at set intervals. After these auctions, SALtok owners receive the relevant benefits, but are subject to 

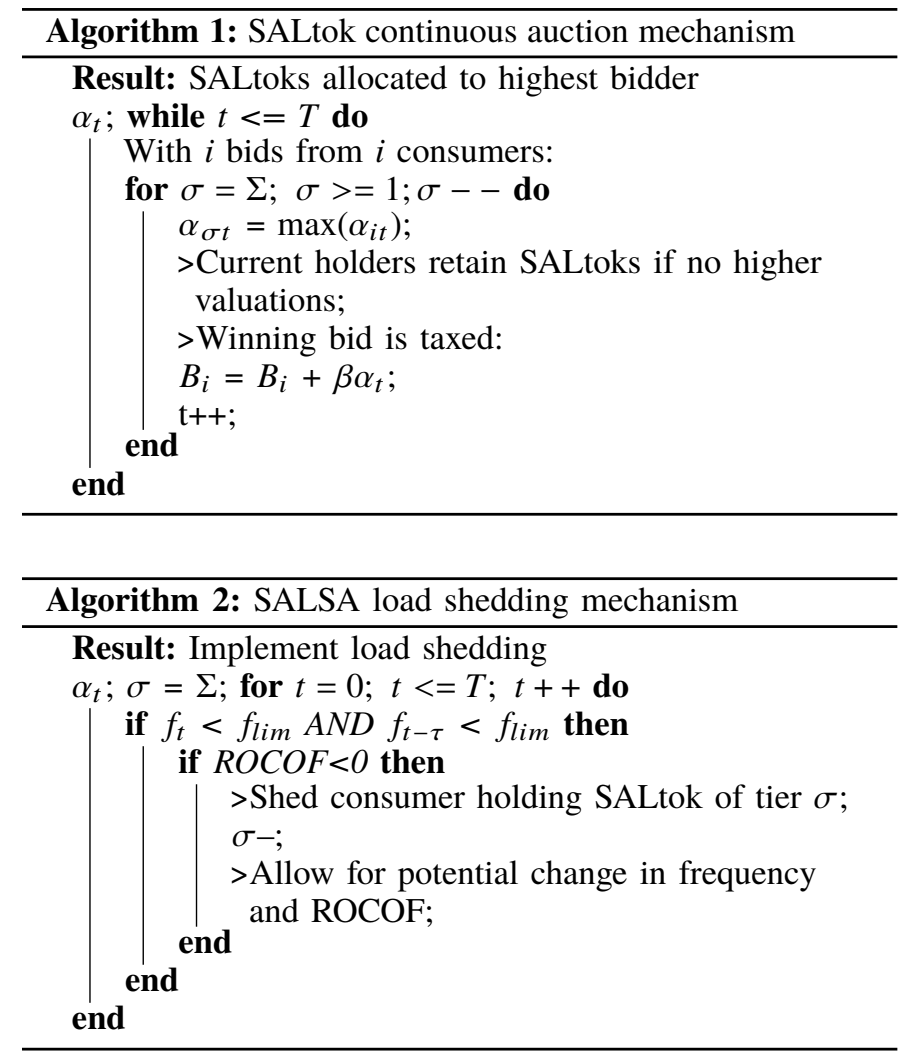

taxes based on their valuation. A portion of currency is held as collateral when a SALtok is purchased, serving to enforce the payment of taxes. Shown below is Algorithm 1, which describes the auction and taxing mechanisms. Furthermore, Algorithm 2 shows how consumers are affected when load shedding is implemented.

In comparison to other methods, such as traditional rolling blackouts, the SALSA-based approach may prove to be more useful to all parties. Consumers can gain ad-hoc access to some immunity from load shedding, while the grid operator has less pressure on generation. The increased income from taxes can be put towards system upgrades, thus increasing the public benefits.

For algorithm 1 and 2:

- $\quad i$ is the consumer index,

- $\quad I$ is the total number of consumers,

- $t$ is period index,

- $\quad T$ is the total period ${ }^{1}$,

- $R O C O F$ is the Rate of Change of Frequency,

- $\sigma$ is the SALSA rank,

- $\quad \Sigma$ is the total number of SALSA ranks (equal to number of consumers),

\footnotetext{
${ }^{1}$ for a realistic system, $T$ would be continuous and therefore infinite.
}

- $f_{t}$ is the grid frequency in period $t$,

- $\quad f_{\text {lim }}$ is frequency limit at which load shedding is implemented for SALtok holders of rank $\sigma$,

- $\tau$ is the time before load shedding is implemented after $f_{\text {lim }}$ is reached,

- $\alpha_{i t}$ is the SALtok valuation/bid for consumer $i$ in period $t$,

- $\alpha_{\sigma t}$ is the winning (maximum) valuation for SALtok of rank $\sigma$ in period $t$,

- $\quad \beta$ is the $\%$ tax imposed on SALtoks per period, and

- $\quad B_{i}$ is the total tax gathered from consumer $i$.

Smart contracts have potential as disruptive evolutionary technology, as in [23]. This scheme could be implemented by a smart contract ecosystem where the purchase of a SALtok guarantees a level of service from the utility. This is a true code is law arrangement that relies only on the continued existence of the framework it is implemented on a public blockchainbased smart contract, such as Ethereum.

\section{Test System}

To test the methodology developed in Section II, a case study example is examined. The case study considers an island power system utilising local generation. This fleet of ten $450 \mathrm{~kW}$ diesel generators is subject to frequent failures, and is often unable to meet demand. Furthermore, the island is vulnerable to inclement weather conditions, which may affect the supply system. Thus, load shedding is implemented to prevent total system collapse. It is assumed that all participating parties have smart meters installed capable of interacting with the unique blockchain facilitating the transfer of SALtoks. Furthermore, it is assumed that these meters can detect grid frequency, and will automatically implement load shedding when the relevant circumstances occur. Smart meters will open and close a circuit breaker based on both the state of the smart contract and current grid frequency. The smart contract collateralises a portion of currency for each consumer equal to their SALtok bid, which serves to enforce tax payments. This paper does not consider the case of consumer reconnection, but it is assumed that generators can signal their reconnection which will trigger a gradual restoration of supply to load shed consumers.

It should be noted that while the SALSA mechanism is developed as a system-wide method of handling load shedding, for simplicity the test case only examines this small island power system.

A set of 30 consumers make up the example island power system, as shown in Table I. These parties include data centres, factories, hospitals, residential neighbourhoods and office districts. Figure 1 shows a mock-up of the island test system. There are thus 30 SALtoks in use, representing the order of load shedding whenever under-frequency conditions occur. 
TABLE I.

Consumers

\begin{tabular}{|c|c|c|}
\hline Consumer & Description & Average demand \\
\hline Consumer 1 & Data Centre & $72 \mathrm{~kW}$ \\
\hline Consumer 2 & Data Centre & $357 \mathrm{~kW}$ \\
\hline Consumer 3 & Office District & $10 \mathrm{~kW}$ \\
\hline Consumer 4 & Office District & $117 \mathrm{~kW}$ \\
\hline Consumer 5 & Factory & $131 \mathrm{~kW}$ \\
\hline Consumer 6 & Data Centre & $180 \mathrm{~kW}$ \\
\hline Consumer 7 & Hospital & $252 \mathrm{~kW}$ \\
\hline Consumer 8 & Office District & $33 \mathrm{~kW}$ \\
\hline Consumer 9 & Data Centre & $141 \mathrm{~kW}$ \\
\hline Consumer 10 & Residential Neighbourhood & $82 \mathrm{~kW}$ \\
\hline Consumer 11 & Residential Neighbourhood & $31 \mathrm{~kW}$ \\
\hline Consumer 12 & Residential Neighbourhood & $163 \mathrm{~kW}$ \\
\hline Consumer 13 & Factory & $253 \mathrm{~kW}$ \\
\hline Consumer 14 & Office District & $21 \mathrm{~kW}$ \\
\hline Consumer 15 & Factory & $209 \mathrm{~kW}$ \\
\hline Consumer 16 & Data Centre & $275 \mathrm{~kW}$ \\
\hline Consumer 17 & Data Centre & $669 \mathrm{~kW}$ \\
\hline Consumer 18 & Office District & $40 \mathrm{~kW}$ \\
\hline Consumer 19 & Office District & $78 \mathrm{~kW}$ \\
\hline Consumer 20 & Data Centre & $336 \mathrm{~kW}$ \\
\hline Consumer 21 & Data Centre & $47 \mathrm{~kW}$ \\
\hline Consumer 22 & Office District & $33 \mathrm{~kW}$ \\
\hline Consumer 23 & Office District & $41 \mathrm{~kW}$ \\
\hline Consumer 24 & Data Centre & $542 \mathrm{~kW}$ \\
\hline Consumer 25 & Residential Neighbourhood & $21 \mathrm{~kW}$ \\
\hline Consumer 26 & Residential Neighbourhood & $11 \mathrm{~kW}$ \\
\hline Consumer 27 & Residential Neighbourhood & $11 \mathrm{~kW}$ \\
\hline Consumer 28 & Residential Neighbourhood & $5 \mathrm{~kW}$ \\
\hline Consumer 29 & Data Centre & $218 \mathrm{~kW}$ \\
\hline Consumer 30 & Office District & $35 \mathrm{~kW}$ \\
\hline
\end{tabular}

1) List of assumptions: Below are a list of assumptions for the specific test case and simulation.

- All parties have blockchain-enabled smart meters installed.

- These meters can detect supply frequency and will automatically disconnect when required.

- Valuations are collateralised with currency for each consumer i.e. payments are enforced.

- Larger consumers are more willing to bid on SALtoks.

- Taxes are received by the governing body of the island.

- All generators in the power system are identical and have the same $\mathrm{H}$-value.

- $\quad$ ROCOF behaves predictably and does not significantly overshoot $f_{n}$ when frequency is recovering.

- Consumers' demand stay constant over each $24 \mathrm{~h}$ period.

- Generators can signal the smart contract when they are returned to working order, triggering a gradual reconnection of consumers that were shed.

\section{Results}

This section examines and discusses the results of SALtok valuations, as well as the system's response during instances of load shedding.
TABLE II.

SALtok Owners and Valuation

\begin{tabular}{lll} 
SALSA rank & Valuation & Owner \\
\hline 1 & na & Consumer 7 \\
2 & $€ 614$ & Consumer 17 \\
3 & $€ 594$ & Consumer 24 \\
4 & $€ 356$ & Consumer 2 \\
5 & $€ 308$ & Consumer 20 \\
6 & $€ 278$ & Consumer 16 \\
7 & $€ 274$ & Consumer 13 \\
8 & $€ 237$ & Consumer 29 \\
9 & $€ 229$ & Consumer 15 \\
10 & $€ 184$ & Consumer 6 \\
11 & $€ 169$ & Consumer 12 \\
12 & $€ 149$ & Consumer 9 \\
13 & $€ 128$ & Consumer 5 \\
14 & $€ 114$ & Consumer 4 \\
15 & $€ 87$ & Consumer 10 \\
16 & $€ 86$ & Consumer 19 \\
17 & $€ 78$ & Consumer 1 \\
18 & $€ 49$ & Consumer 21 \\
19 & $€ 42$ & Consumer 23 \\
20 & $€ 41$ & Consumer 18 \\
21 & $€ 35$ & Consumer 30 \\
22 & $€ 5$ & Consumer 8 \\
23 & $€ 3$ & Consumer 22 \\
24 & $€ 2$ & Consumer 11 \\
25 & $€ 1$ & Consumer 14 \\
26 & $€ 0$ & Consumer 25 \\
27 & $€ 0$ & Consumer 26 \\
28 & $€ 0$ & Consumer 27 \\
29 & $€ 0$ & Consumer 3 \\
30 & $€ 0$ & Consumer 28
\end{tabular}

1) SALSA Rankings and Valuations: Table II shows the ranking of the 30 consumers i.e. the hierarchy of load shedding order. Also shown is their SALtok valuation. The SALtok tax imposed per period is set to $\beta=20 \%$. It is assumed that larger consumers are more likely to invest in higher ranking SALtoks, so as to mitigate the effects of unexpected load shedding. Consumer 7 (the hospital) automatically receives the highest ranking SALtok without being subjected to the daily tax.

2) Under-Frequency Trigger Example: To demonstrate the workings on a per-second basis, a one minute period on 27 January is examined. Three generators fail during the inspected period. The scenario is simulated discretely in MatLAB at a time resolution of 0.05 seconds. The ROCOF is calculated as in Equation 1, while generator $H$ values are assumed as 0.6 seconds [24]. Consumers are assumed to keep their demand constant within the considered period. The $f_{\text {lim }}$ value is set to $49.75 \mathrm{~Hz}$ and $\tau=0.1$ seconds. This simulation serves as basic approximation of power system dynamics. It is also assumed that generators do not significantly overshoot $50 \mathrm{~Hz}$.

When the first diesel generator goes offline the frequency begins to decline. A tenth of a second after $f_{\text {lim }}$ is reached load shedding is automatically activated. The first frequency nadir results in the deactivation of nine consumers, starting with the lowest SALtok holder. Consumers 28, 3, 27, 26, 25, 14, 11, 22 and 8 are removed in that order. The ROCOF value becomes positive and the frequency begins to rise. Before the system can fully recover, a second generator fails, and frequency again declines. Load shedding is again activated and another 


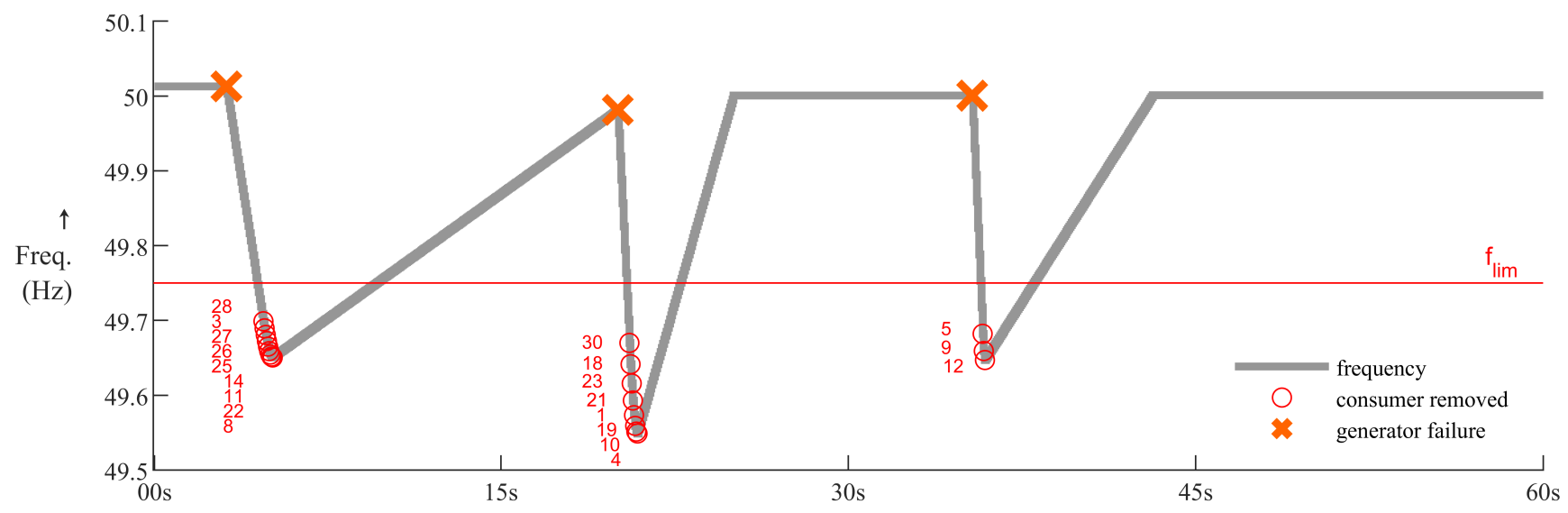

Fig. 2. Frequency change sample from 27 January

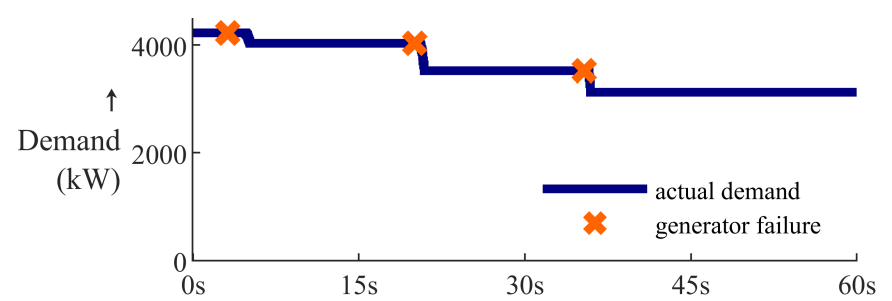

Fig. 3. Demand over 60 second period

eight consumers are removed from supply. These consumers are numbers $30,18,23,21,1,19,10$ and 4 . After rated frequency is restored, a third generator fails and frequency drops again. A final three consumers are disconnected before the system begins to recover, namely Consumers 5, 9 and 12. This is illustrated in Figure 2. The moment where each consumer is removed from supply, as well as the moment or generator failure are also shown in Figure 2. The lower $f_{\text {lim }}$ threshold is added for reference. Figure 3 shows the total system demand over the examined period. The rapid reductions when consumers are removed from supply are visible when $f_{\text {lim }}$ is reached.

3) Long-Term Example with Taxation: To show the effects of holding SALtoks over an extended period, a long-term example is constructed. The examined period considers daily values over four weeks, from Monday 1 January to Sunday 28 January. Figure 4 shows the reduction in supply over the considered period. Once again MATLAB is used to simulate the individual scenarios, and establish how many consumers are removed from supply.

There are four instances of load shedding in the considered period (including the example above), with varying degrees of severity. Each day works in the same manner as in Section IV-2. The days where load shedding occurs and the affected consumers are shown below, along with the reduced demand each day. It can be seen that usually removing a number of the smaller consumers is enough to stabilise the power system.

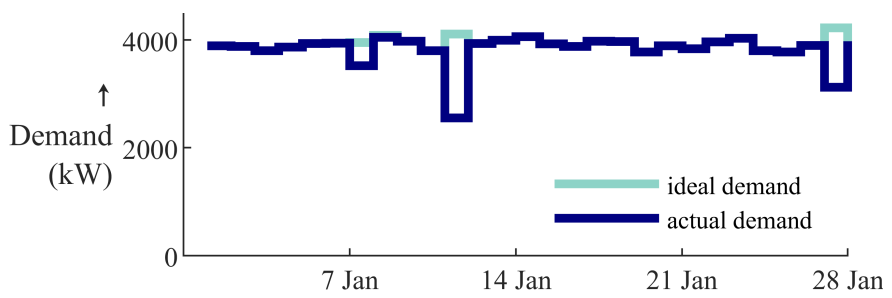

Fig. 4. Demand and respective load shedding levels

At points, such as on 7 January, as many as 14 consumers are disconnected, resulting in a loss of only $11 \%$ of demand. However, the emergency situation on the 11th of January sees 23 consumers losing supply, resulting in a $38 \%$ reduction in total system load.

The taxing mechanism results in an income of $€ 22753$ over the four week period. Therefore, although smaller consumers bear the brunt of supply interruptions, they ultimately see the benefits of significant additional public funds gathered from larger consumers.

\section{Conclusions}

This piece served as an exploratory study into combining a blockchain-aware smart meter ecosystem with a radical and disruptive economic model, in the form of SALSA. These ideas were used to formulate the novel smart contract-based load shedding hierarchy paradigm. Emphasis was placed on examining the viability of this radical cyber-physical model, rather than any blockchain- or power systems engineering methods. The piece assumes the workings of smart meters that observes grid conditions and the instantaneous state of the smart contract before making a decision on the state of its circuit breaker.

Ultimately, the method allows larger consumers to potentially avoid load shedding. These parties tend to be data centres, factories and office facilities i.e. economic drivers. Thus, the economic impacts of reduced electrical supply are reduced. 
TABLE III.

LOAD SHEDDING INCIDENTS

\begin{tabular}{llll} 
Date & $\begin{array}{l}\text { Number of } \\
\text { Consumer } \\
\text { Affected }\end{array}$ & Consumers Affected & $\begin{array}{c}\text { Generation Capacity } \\
\text { Reduction }\end{array}$ \\
\hline 7 Jan & 14 & $28,3,27,26,25,14,11,22,8,30,18,23,21,1$ & $900 \mathrm{~kW}$ \\
8 Jan & 4 & $28,3,27,26$ & $450 \mathrm{~kW}$ \\
11 Jan & 23 & $28,3,27,26,25,14,11,22,8,30,18,23,21,1,19,10,4,5,9,12,6,15,29$ & $1800 \mathrm{~kW}$ \\
27 Jan & 9 & $28,3,27,26,25,14,11,22,8$ & $1350 \mathrm{~kW}$
\end{tabular}

If the traditional rolling blackout method were implemented, many of these parties would likely need to cease operation, or would need to invest in expensive private backup generation. Consumers may bid on higher-ranked SALtoks when supplysensitive activities are scheduled. While high ranking SALtoks are ubiquitously held by large-scale consumers, smaller consumers will see the societal benefit of the extra taxes gathered from SALSA holders. Critical facilities, like hospitals, can be added to the top of the hierarchy to most-effectively curtail risk of loss of supply. Further studies may also consider the undervoltage scenario, and could potentially combine this with the frequency-based approach discussed in this piece.

\section{REFERENCES}

[1] C. Concordia, L. H. Fink, and G. Poullikkas, "Load shedding on an isolated system," IEEE Transactions on Power Systems, vol. 10, no. 3, pp. 1467-1472, 1995.

[2] T. Shekari, A. Gholami, F. Aminifar, and M. Sanaye-Pasand, "An adaptive wide-area load shedding scheme incorporating power system real-time limitations," IEEE Systems Journal, vol. 12, no. 1, pp. 759-767, 2018.

[3] A. Goldberg, "The economic impact of load shedding: The case of south african retailers," Master's thesis, University of Pretoria, 2015.

[4] K. Aidoo and R. C. Briggs, "Underpowered: Rolling blackouts in Africa disproportionately hurt the poor," African Studies Review, vol. 62, no. 3, pp. 112-131, 2019. Dor: 10.1017/asr 2018.78.

[5] B. Otomega, M. Glavic, and T. Van Cutsem, "Distributed undervoltage load shedding," IEEE Transactions on Power Systems, vol. 22, no. 4, pp. 2283-2284, 2007. Dor: 10.1109/ TPWRS.2007.907589.

[6] C. W. Taylor, "Concepts of undervoltage load shedding for voltage stability," IEEE Transactions on Power Delivery, vol. 7 , no. 2 , pp. $480-488,1992$.

[7] V. C. Nikolaidis and C. D. Vournas, "Design strategies for load-shedding schemes against voltage collapse in the hellenic system," IEEE Transactions on Power Systems, vol. 23, no. 2, pp. 582-591, 2008.

[8] R. M. Maliszewski, R. D. Dunlop, and G. L. Wilson, "Frequency actuated load shedding and restoration part i - philosophy," IEEE Transactions on Power Apparatus and Systems, vol. PAS-90, no. 4, pp. 1452-1459, 1971.

[9] R. Faranda, A. Pievatolo, and E. Tironi, "Load shedding: A new proposal," IEEE Transactions on Power Systems, vol. 22, no. 4, pp. 2086-2093, 2007.

[10] D. Prasetijo, W. R. Lachs, and D. Sutanto, "A new load shedding scheme for limiting underfrequency," IEEE Transactions on Power Systems, vol. 9, no. 3, pp. 1371-1378, 1994.
[11] C. Moors, D. Lefebvre, and T. Van Cutsem, "Design of load shedding schemes against voltage instability," in 2000 IEEE Power Engineering Society Winter Meeting. Conference Proceedings (Cat. No.00CH37077), vol. 2, 2000, 1495-1500 vol.2.

[12] E. M. S. Niou and G. Tan, "An analysis of Dr. Sun Yatsen's self-assessment scheme for land taxation," Public Choice, 1994.

[13] A. C. Harberger and C. Matus Romo, "Issues for tax reform for Latin America," in Conference on Fiscal Policy for Economic Growth in Latin America, Hopkins, 1965, pp. 110-121.

[14] E. G. Weyl and E. A. Posner, Radical Markets. Princeton University Press, 2018.

[15] P. Healy and M. Prewitt, "The handbook for radical local democracy v2.0," 2020.

[16] P. Healy, M. Prewitt, and D. Klingler, "Radically rethinking public purchasing: How new mechanisms can improve efficiency and equality in government spending.," 2019.

[17] A. Butelmann. (2020). Electromagnetic spectrum, SALSA and its allocation in chile - andrea butelmann - rxc 2020, RadicalXChange, [Online]. Available: https://www. youtube. $\mathrm{com} /$ watch? $\mathrm{v}=\mathrm{v} 5 \mathrm{lbRdhBWbc}$.

[18] M. T. Devine and P. Cuffe, "Blockchain electricity trading under demurrage," IEEE Transactions on Smart Grid, vol. 10, no. 2, pp. 2323-2325, 2019.

[19] A. de Villiers and P. Cuffe, "Towards embedding network usage charges within a peer-to-peer electricity marketplace," in 2020 6th IEEE International Energy Conference (ENERGYCon), 2020, pp. 598-603. DoI: 10.1109/ENERGYCon48941. 2020.9236447.

[20] O. Alao and P. Cuffe, "Towards a blockchain special purpose vehicle for financing independent renewable electricity projects in sub-saharan africa," in 2020 6th IEEE International Energy Conference (ENERGYCon), 2020, pp. 1041-1046. DOI: 10.1109/ENERGYCon48941.2020.9236599.

[21] O. Alao and P. Cuffe, Towards a blockchain contract-fordifference financial instrument for hedging renewable electricity transactions, May 2020. DoI: 10.36227/techrxiv.12249308. v2. [Online]. Available: https://www.techrxiv.org/articles/ preprint/Towards_a_Blockchain_Contract - for-Difference _ Financial_Instrument_for_Hedging_Renewable_Electricity_ Transactions_pdf/12249308/2.

[22] D. Doheny and M. Conlon, "Investigation into the local nature of rate of change of frequency in electrical power systems," in 2017 52nd International Universities Power Engineering Conference (UPEC), 2017, pp. 1-6. DOI: 10.1109/UPEC.2017. 8231982.

[23] A. de Villiers and P. Cuffe, "A three-tier framework for understanding disruption trajectories for blockchain in the electricity industry," IEEE Access, vol. 8, pp. 65670-65 682, 2020.

[24] Importance of inertia in island power systems, 2016. [Online]. Available: http://www.sigmapower.com.au/24/. 